\title{
Adverse effects of cigarette smoking on exhaled breath carbon monoxide, blood carboxyhemoglobin, and hematological parameters amongst Sri Lankan adult tobacco smokers: A descriptive study
}

\author{
Prasanna Herath ${ }^{1}$, Savithri W. Wimalasekera ${ }^{2}$, Thamara D. Amarasekara ${ }^{3}$, Manoj S. Fernando ${ }^{4}$, Sue Turale ${ }^{5}$
}

\section{AFFILIATION}

1 Department of Nursing and Midwifery, Faculty of Allied Health Sciences, General Sir John Kotelawala Defence University, Colombo, Sri Lanka 2 Faculty of Medical Sciences, Department of Physiology, University of Sri Jayewardenepura, Nugegoda, Sri Lanka

3 Department of Nursing and Midwifery, Faculty of Allied Health Sciences, University of Sri Jayewardenepura, Nugegoda, Sri Lanka

4 Department of Health Promotion, Faculty of Applied Sciences, Rajarata University of Sri Lanka, Anuradhapura, Sri Lanka

5 Faculty of Nursing, Chiang Mai University, Chiang Mai, Thailand

CORRESPONDENCE TO

Prasanna Herath. Department of Nursing and Midwifery, Faculty of
Allied Health Sciences, General Sir John Kotelawala Defence University, Kandawala Road, Dehiwala-Mount Lavinia 10390, Colombo, Sri Lanka. E-mail: prasannah@kdu.ac.lk ORCID ID: https://orcid.org/0000-00016470-2229

\section{KEYWORDS}

tobacco smoking, Brinkman index, exhaled breath carbon monoxide (eCO), carboxyhemoglobin ( $\mathrm{COHb} \%)$, hemoglobin $(\mathrm{Hb})$

Received: 28 June 2021, Revised: 12 September 2021, Accepted: 14 October 2021

https://doi.org/10.18332/popmed/143076
RESULTS Smokers had significantly higher values of eCO, COHb\%, Hemoglobin ( $\mathrm{Hb})$, Hematocrit (HCT), Mean Corpuscular Volume (MCV), Mean Corpuscular Hemoglobin $(\mathrm{MCH})$, Mean Corpuscular Hemoglobin Concentration (MCHC), total White Blood Cell total count (WBC), Lymphocyte count, Monocyte count, and Granulocyte count. The number of cigarettes per day, duration of smoking, and Brinkman index were positively correlated with eCO and $\mathrm{COHb} \%$. MCV and MCH were positively correlated with the number of cigarettes smoked per day, smoking duration, and Brinkman index.

CONCLUSIONS The severity of smoking can be quantified by the exhaled breath $\mathrm{CO}$ and blood $\mathrm{COHb} \%$ levels as these parameters correlate with the severity of smoking. Hematological parameters of smokers were affected with continued long-term low-intensity smoking.

\section{INTRODUCTION}

Smoking is a leading preventable cause of death and illness worldwide ${ }^{1,2}$. Smoking has a detrimental effect on the smoker's life expectancy and has a major economic impact on the family ${ }^{3,4}$. Annual mortality totals 8 million people, with 7 million of these fatalities directly attributable to tobacco usage ${ }^{5,6}$. Over $80 \%$ of the 1.3 billion tobacco smokers worldwide live in low- and middle-income countries ${ }^{7,8}$ and tobacco smoking is a critical health issue in Sri Lanka, claiming over 20000 lives each year'. According to WHO statistics, $29.4 \%$ of Sri Lankan males are smoking tobacco ${ }^{10,11}$, and amongst them $19.5 \%$ smoke daily ${ }^{12}$. Smoking is a wellestablished risk factor for the development of a range of diseases ${ }^{13,14}$ including major cardiovascular diseases $(\mathrm{CVD})^{15,16}$, chronic obstructive pulmonary disease (COPD) ${ }^{17,18}$, and some cancers ${ }^{19,20}$. Tobacco smoke contains a variety 
of chemicals known to be harmful to human health. Free radicals, nicotine, and carbon monoxide (CO) are believed to be the most important for pharmacological actions ${ }^{21}$.

Smoking increases the level of $\mathrm{CO}$ in the blood, which may lead to several cardiovascular diseases (CVD). CO displaces oxygen in the red blood cell to form $\mathrm{COHb} \%{ }^{22}$. Measurement of $\mathrm{CO}$ in exhaled breath (eCO ppm) and carboxyhemoglobin $(\mathrm{COHb} \%)$ is a non-invasive, objective measure to assess smoking status and has been successfully used in several studies ${ }^{16,22-24}$. Studies have reported that smoking increases the level of hematologic parameters such as hemoglobin (HB), red blood cells (RBCs), neutrophils, eosinophils, monocytes, and platelets while smoking cessation was associated with a decrease in these values among smokers ${ }^{13,22,25,26}$. All blood cells are produced in the bone marrow and they mature in the peripheral blood tissue. These haemopoietic mechanisms can be affected when exposed to the harmful substances in cigarette smoke, and tobacco contains more than four thousand chemicals that may affect haemopoiesis ${ }^{21}$.

However, the information regarding the effect of smoking on blood $\mathrm{COHb} \%$ and hematological parameters is scarce ${ }^{21}$. According to the best of the authors' knowledge, the relationship of smoking with eCO, $\mathrm{COHb} \%$, red cell parameters, and white cell parameters have not been studied in a South Asian population, according to the available literature. Accordingly, the study investigates the duration of smoking and effects of smoking severity on eCO, $\mathrm{COHb} \%$, and hematological parameters. Thus, it provides new data for a South Asian population that does not smoke as heavily as the Far-Eastern Asian populations ${ }^{12}$.

At the moment, Sri Lanka does not have baseline values for the above-measured variables in its smoking population. These baseline values and correlations will be critically important when policymakers develop studies on smoking cessation. On the other hand, Sri Lanka has the secondlowest prevalence of daily smoking in South Asia, trailing only India ${ }^{12}$. Bangladesh, Maldives, Myanmar, Nepal, and Thailand, all have a greater smoking prevalence than Sri Lanka ${ }^{12}$. Personal cigarette usage in Sri Lanka is also lower than in other Asian countries ${ }^{27}$. As a result, additional research into the physiological response to this low intensity of tobacco smoking is needed. We also wanted to check existing values with South Asian populations where studies are scarce. Thus, the current study is one of the first studies conducted in Sri Lanka to investigate the above parameters with an objective measure of the severity of smoking using eCO levels ${ }^{27}$.

\section{METHODS}

\section{Study design and setting}

A descriptive cross-sectional study was conducted in selected peri-urban MOH (Medical officer of Health area) divisions named Piliyandala, Homagama, Boralesgamuwa, and Ratmalana, in the Colombo district of Sri Lanka.

\section{Participants and sample size}

A descriptive study was conducted on adult male daily tobacco smokers $(n=360)$ aged $21-60$ years with a smoking history of at least five years. They were randomly selected from peri-urban areas of Colombo district, Sri Lanka. A comparison group of 180 non-smokers was randomly chosen from the same location and matched for age, height, and weight. Non-smokers were defined as respondents who stated at the time of enrolment that they had never smoked or had not smoked in the previous five years, as well as had not smoked more than 100 cigarettes in their lifetime 28,29 .

Female smoking frequency is very low in Sri Lanka. It is about $0.2 \%{ }^{12}$ as smoking among females is considered a cultural taboo in Sri Lanka. Due to the fact that female smoking prevalence is so low in comparison to male smoking prevalence, we excluded female smokers and thus studied only male subjects to represent the smoking community. Thus, this study was conducted on male smokers.

Smokers and non-smokers with a history of myocardial infarction within the previous 4 weeks, diagnosis of alcohol dependence in the previous six months, or drinking six or more drinks on six or more days a week were excluded. Smokers with psychiatric disorders were also excluded, as smoking prevalence is known to be higher in those with psychiatric illnesses than in the general population ${ }^{30,31}$.

All participants providing informed written consent and fulfilling the recruitment criteria were included. Confidentiality of all information and identities of participants were strictly maintained and were not disclosed. The sample was randomly selected from the electoral registers of each Grama Niladhari (GN) Office. The electoral register for the year 2016 was used for this purpose.

\section{Data collection}

An interviewer-administered questionnaire was used to obtain information on participants' baseline data, such as occupation, age, number of years of smoking, frequency, and type of tobacco smoking. Information sheets and consent forms were translated to the local languages of Sinhala and Tamil to ensure that it was accessible, easily understood, and available to all members. The participation was voluntary and the subject had the right to withdraw from participation at any time. The anthropometric measurements of height and weight were obtained using standardized measurement techniques using a stadiometer (KT-GF06A-Kindcare- China) and a portable electronic bathroom scale (Omron HN-283Japan). All equipment used were calibrated daily and periodically assessed for accuracy.

$\mathrm{COHb} \%$ and eCO levels were measured using a calibrated portable Bedfont Micro+ ${ }^{\mathrm{TM}}$ Smokerlyzer ${ }^{\circledR}$ (Bedfont Scientific, UK). The measuring concentration range of the device is $0-500 \mathrm{ppm}$ (parts per million). Measurement of eCO was performed after a minimum time interval of 30 minutes after the last cigarette, as recommended by the manufacturer. Participants were asked to exhale completely, 
inhale completely, hold for 15 seconds, and then exhale with a disposable mouthpiece. The Smokerlyser (Bedfont ${ }^{\circledR}$ ) measures exhaled breath carbon monoxide level (eCO) based on the conversion of $\mathrm{CO}$ to carbon dioxide $\left(\mathrm{CO}_{2}\right)$ over a catalytically active electrode. $\mathrm{COHb} \%$ levels were automatically calculated based on eCO levels by the device. The smoking severity was estimated based on the Brinkman index, which is calculated by multiplying the duration of smoking (in years) by the number of cigarettes smoked per day $^{32-34}$.

An aseptically collected sample of venous blood was analyzed to determine the full blood count (FBC) on randomly selected 180 smokers and 180 non-smokers. The 180 smokers were systematically selected based on the smoking severity: mild smokers $(\mathrm{n}=60)<2$ cigarettes/day, moderate smokers $(n=60)>2$ and $<10$ cigarettes/day, and severe smokers $(n=60)>10$ cigarettes/day, based on the available literature ${ }^{35,36}$. Assessment of full blood count was done by an automated Coulter blood cell counter (Beckmann Coulter Inc. US). Participants identified with abnormal test results were referred to the university medical clinic for further management. The consent form, datasheet, and other data were securely stored.

\section{Statistical analysis}

Statistical analysis was performed with SPSS version 23.0
(SPSS Inc.). The normal distribution and the similarity of the variances were tested with the Kolmogorov-Smirnov test before statistical analysis. Groups were compared by Student's t-test for normally distributed data and MannWhitney U test for skewed distributions. The correlations between the normally distributed parameters were analyzed using the Pearson correlation coefficient and Spearman's rank-order correlation test was used for skewed data. Data are expressed as means with standard deviation (SD) and medians with interquartile range. The level of significance was set at $\mathrm{p}<0.05$.

\section{RESULTS}

\section{Baseline characteristics of smokers and non-smokers}

There was no statistically significant difference between age and anthropometric measurements of height, weight, and BMI $\left(\mathrm{kg} / \mathrm{m}^{2}\right)$ between smokers and non-smokers ( $\left.\mathrm{p}>0.05\right)$. Smokers' mean $( \pm$ SD) value of daily cigarette consumption was $5.73 \pm 4.88$ sticks/day, smoking duration was $22 \pm 12.63$ years, and smoking-initiation age was $18.7 \pm 4.47$ years. The median $( \pm \mathrm{IQR})$ value of the Brinkman index was $80.0 \pm 132.0$ (Table 1 ).

\section{$\mathrm{COHb} \%$ and eCO levels of smokers and non-smokers}

Statistically significant high levels of eCO (ppm) $(\mathrm{p}<0.001)$ and $\mathrm{COHb} \%$ were observed among smokers compared to non-smokers $(p<0.001)$ (Table 2). This indicates that the

Table 1. Baseline characteristics of smokers and non-smokers

\begin{tabular}{|c|c|c|c|c|c|}
\hline \multirow[t]{2}{*}{ Characteristics } & \multicolumn{2}{|c|}{$\begin{array}{l}\text { Smokers } \\
(n=360)\end{array}$} & \multicolumn{2}{|c|}{$\begin{array}{c}\text { Non-smokers } \\
(\mathrm{n}=180)\end{array}$} & \multirow[t]{2}{*}{ p } \\
\hline & Mean & SD & Mean & SD & \\
\hline Age (years) & 41.00 & 11.77 & 42.10 & 12.63 & 0.263 \\
\hline Weight (kg) & 65.35 & 12.84 & 65.20 & 11.29 & 0.897 \\
\hline Height $(\mathrm{cm})$ & 166.18 & 6.62 & 166.68 & 7.91 & 0.492 \\
\hline BMI $\left(\mathrm{kg} / \mathrm{m}^{2}\right)$ & 23.70 & 4.43 & 23.71 & 3.86 & 0.973 \\
\hline Cigarettes/day & 5.73 & 4.88 & - & - & - \\
\hline Smoking duration (years) & 22.00 & 12.63 & - & - & - \\
\hline Smoking-initiation age (years) & 18.70 & 4.47 & - & - & - \\
\hline Brinkman index, median (IQR) & 80.00 & 132.00 & & & \\
\hline
\end{tabular}

Student's t test, $\mathrm{p}<0.05$.

Table 2. COHb\% and eCO levels of smokers and non-smokers

\begin{tabular}{|c|c|c|c|c|c|}
\hline \multirow[t]{2}{*}{ Variable } & \multicolumn{2}{|c|}{$\begin{array}{l}\text { Smokers } \\
(n=360)\end{array}$} & \multicolumn{2}{|c|}{$\begin{array}{c}\begin{array}{c}\text { Non-smokers } \\
(\mathrm{n}=180)\end{array} \\
\end{array}$} & \multirow[t]{2}{*}{$\mathbf{p}^{*}$} \\
\hline & Median & IQR & Median & IQR & \\
\hline Exhaled carbon monoxide (eCO ppm) & 7.00 & 8.00 & 3.00 & 1.00 & $<0.001$ \\
\hline Carboxyhaemoglobin\% (COHb\%) & 1.75 & 1.28 & 0.95 & 0.16 & $<0.001$ \\
\hline
\end{tabular}

*Mann-Whitney U test, $\mathrm{p}<0.001$. 
Table 3. Comparison of hematological parameters between smokers and non-smokers

\begin{tabular}{|c|c|c|c|c|c|}
\hline \multirow[t]{2}{*}{ Hematological parameters } & \multicolumn{2}{|c|}{$\begin{array}{l}\text { Smokers } \\
(\mathrm{n}=360)\end{array}$} & \multicolumn{2}{|c|}{$\begin{array}{c}\text { Non-smokers } \\
(\mathbf{n}=\mathbf{1 8 0})\end{array}$} & \multirow[t]{2}{*}{$\mathbf{p}$} \\
\hline & Median & IQR & Median & IQR & \\
\hline $\mathrm{RBC}\left(\times 10^{12} / \mathrm{L}\right)$ & 5.22 & 0.77 & 5.32 & 0.94 & 0.160 \\
\hline $\mathrm{HGB}(\mathrm{g} / \mathrm{dL})$ & 14.70 & 2.00 & 14.10 & 2.53 & $<0.001^{* *}$ \\
\hline НСТ\% & 45.50 & 7.20 & 44.50 & 7.50 & $0.004^{*}$ \\
\hline MCV (fL) & 87.00 & 6.30 & 84.20 & 7.55 & $<0.001^{* *}$ \\
\hline MCH (pg) & 28.40 & 1.80 & 27.40 & 2.75 & $<0.001^{* *}$ \\
\hline MCHC (g/dL) & 32.50 & 1.80 & 32.00 & 2.10 & $0.001^{*}$ \\
\hline WBC $\left(\times 10^{9} / \mathrm{L}\right)$ & 7.70 & 2.00 & 7.00 & 1.70 & $<0.001^{* *}$ \\
\hline $\operatorname{PLT}\left(\times 10^{9} / \mathrm{L}\right)$ & 239.00 & 59.00 & 250.00 & 76.25 & 0.205 \\
\hline Lymphocytes $\left(\times 10^{9} / \mathrm{L}\right)$ & 2.90 & 1.00 & 2.60 & 0.83 & $0.023^{*}$ \\
\hline Monocytes $\left(\times 10^{9} / \mathrm{L}\right)$ & 0.60 & 0.20 & 0.50 & 0.20 & $<0.001^{* *}$ \\
\hline Granulocytes $\left(\times 10^{9} / \mathrm{L}\right)$ & 3.90 & 1.50 & 3.60 & 1.70 & $<0.001^{* *}$ \\
\hline
\end{tabular}

Mann-Whitney U test; ${ }^{* *} \mathrm{p}<0.001,{ }^{*} \mathrm{p}<0.05$.

CO arising from the smoke was efficiently bound to the hemoglobin in red blood cells.

\section{Comparison of hematological parameters between smokers and non-smokers}

The smokers had significantly higher Hb, HCT, MCV, MCH, and MCHC, WBC counts, lymphocyte count, monocytes count, and granulocytes count, compared to the non-smokers (Table 3). This would be mostly stimulated by the hypoxia caused by the $\mathrm{CO}$ bound $\mathrm{Hb}$ being unable to transport $\mathrm{O} 2$ to tissues efficiently, thus a rise in erythropoietin would result in the increase in hematological parameters.

\section{Correlation of smoking variables with $\mathrm{eCO}$ and $\mathrm{COHb} \%$ levels}

There was a strong, positive correlation between the number of cigarettes smoked per day with eCO and the $\mathrm{COHb} \%$ levels $(p<0.001)$ (Figure 1). The duration of smoking $(p<0.001)$ (Figure 2) and Brinkman index ( $<<0.001)$ (Figure 3) were also strongly positively correlated with eCO and the $\mathrm{COHb} \%$

Figure 1. Correlation between the number of cigarettes smoked per day with (A) eCO levels, and (B) COHb\% levels of smokers

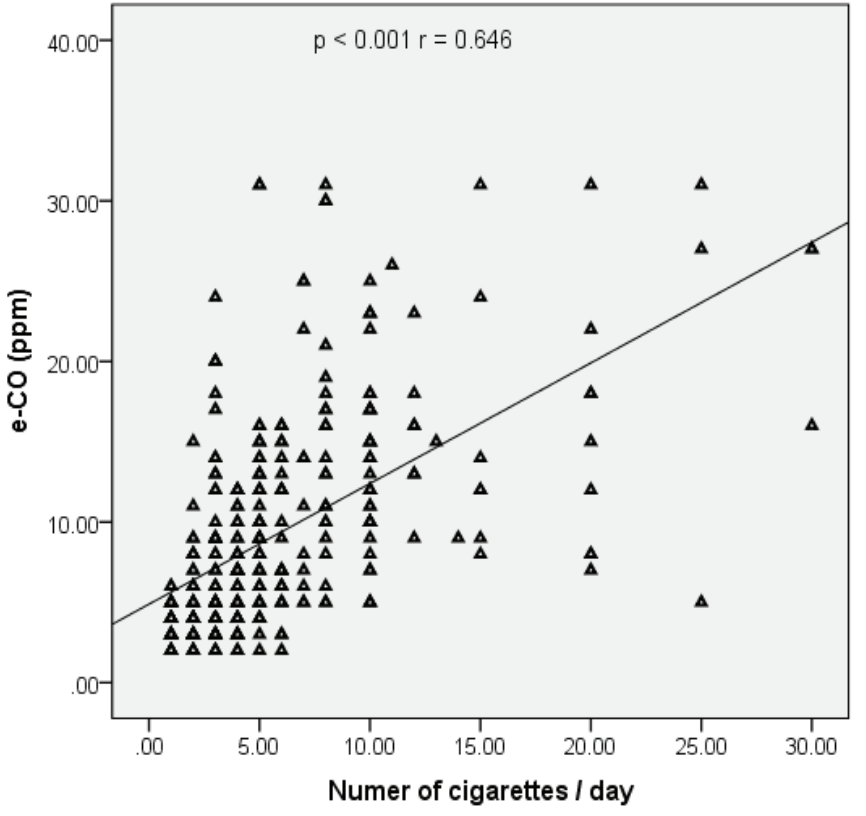

(A)

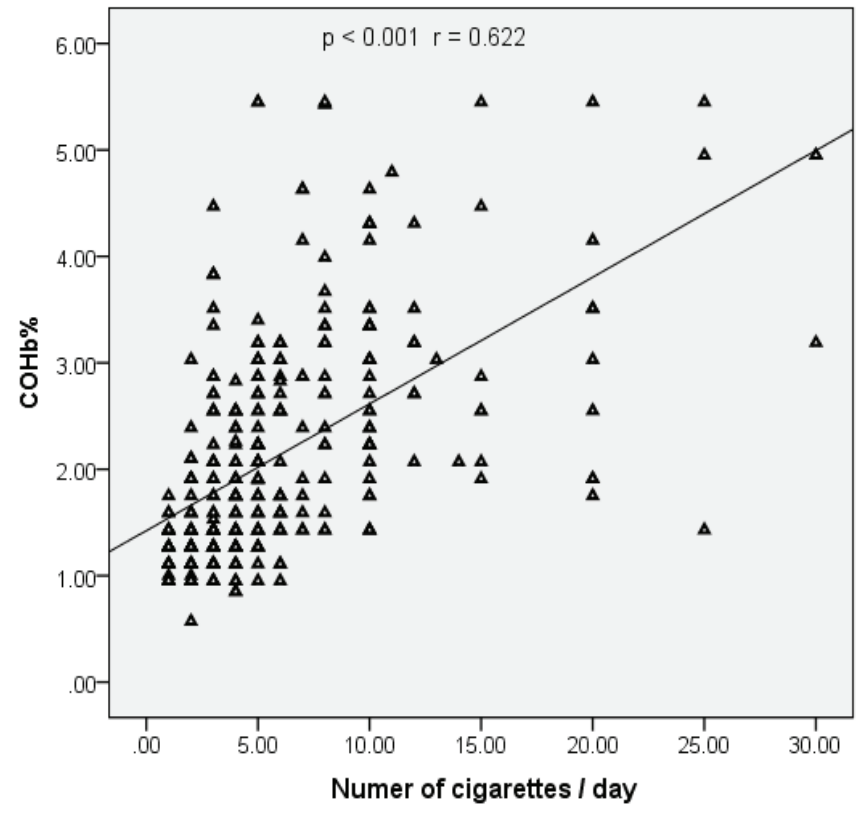

(B) 
levels $(\mathrm{p}<0.001)$. There was a strong negative correlation between the time gap from the last smoked episode with eCO and $\mathrm{COHb} \%$ levels $(\mathrm{p}<0.001)$ (Figure 4).

\section{Correlation between the number of cigarettes smoked} per day and hematological parameters

A Spearman's rank-order correlation test was used to establish the relationship between smoking-related variables and hematological parameters. There was a significant, positive correlation between the number of cigarettes smoked per day and the MCV $(\mathrm{r}=0.148, \mathrm{p}=0.046)$, and the $\mathrm{MCH}(\mathrm{r}=0.184, \mathrm{p}=0.013)$.

\section{Correlation of Brinkman index and hematological parameters}

A Spearman's rank-order correlation test was used to determine the relationship between the Brinkman index and hematological parameters. There was a significant

Figure 2. Correlation between the duration of smoking with (A) eCO levels, and (B) COHb\% levels of smokers

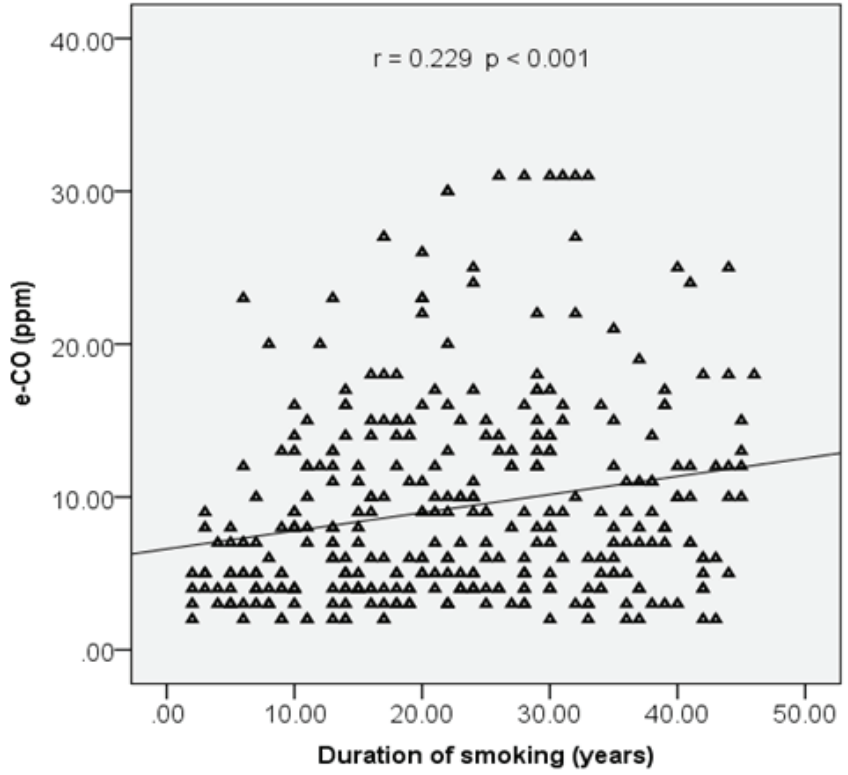

(A)

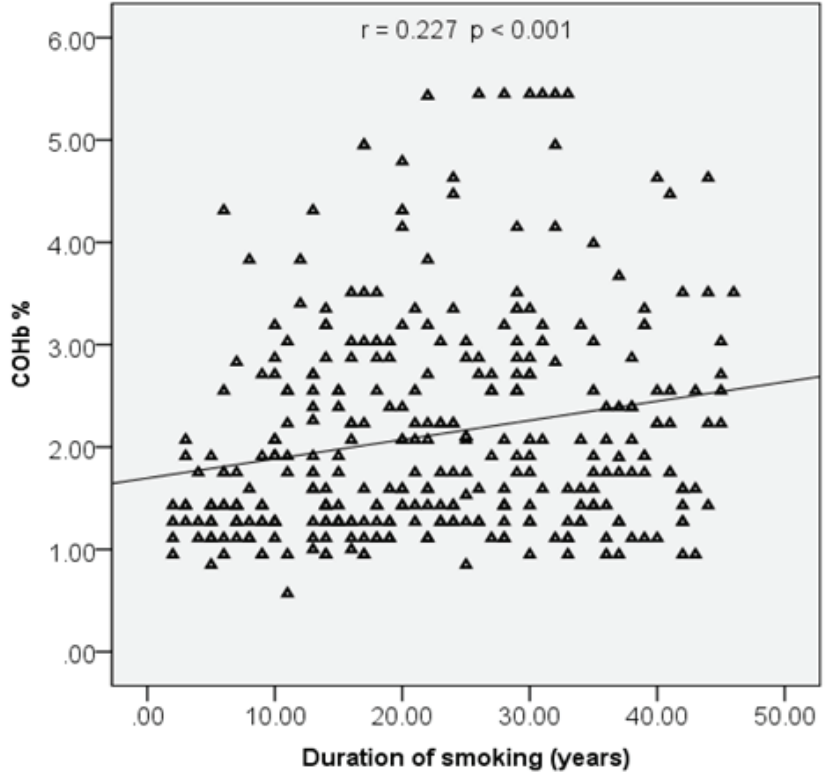

(B)

Figure 3. Correlation between the Brinkman index with (A) eCO levels, and (B) COHb\% levels of smokers

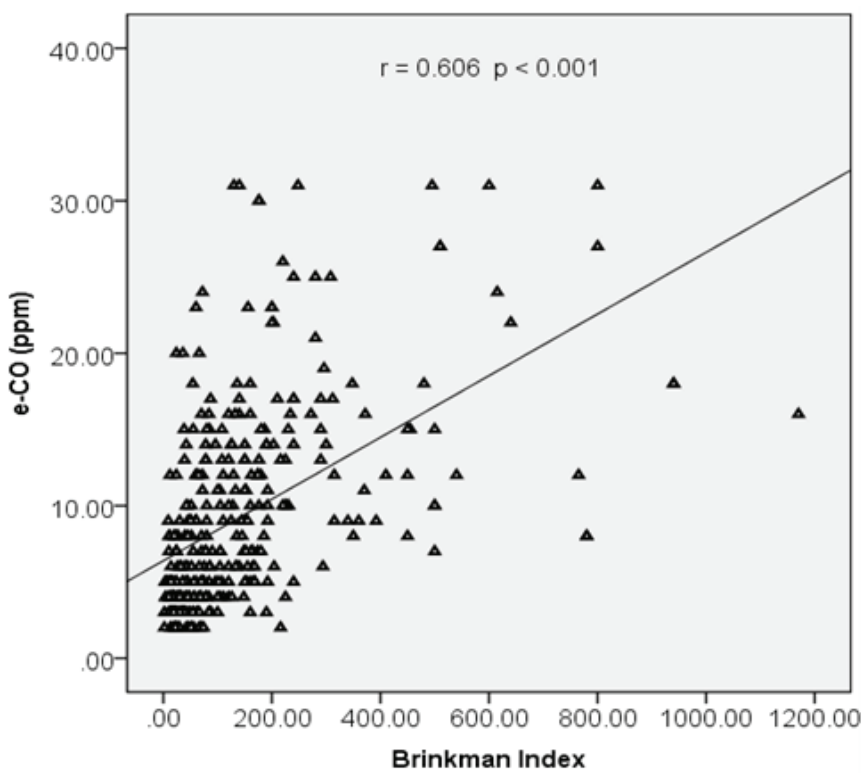

(A)

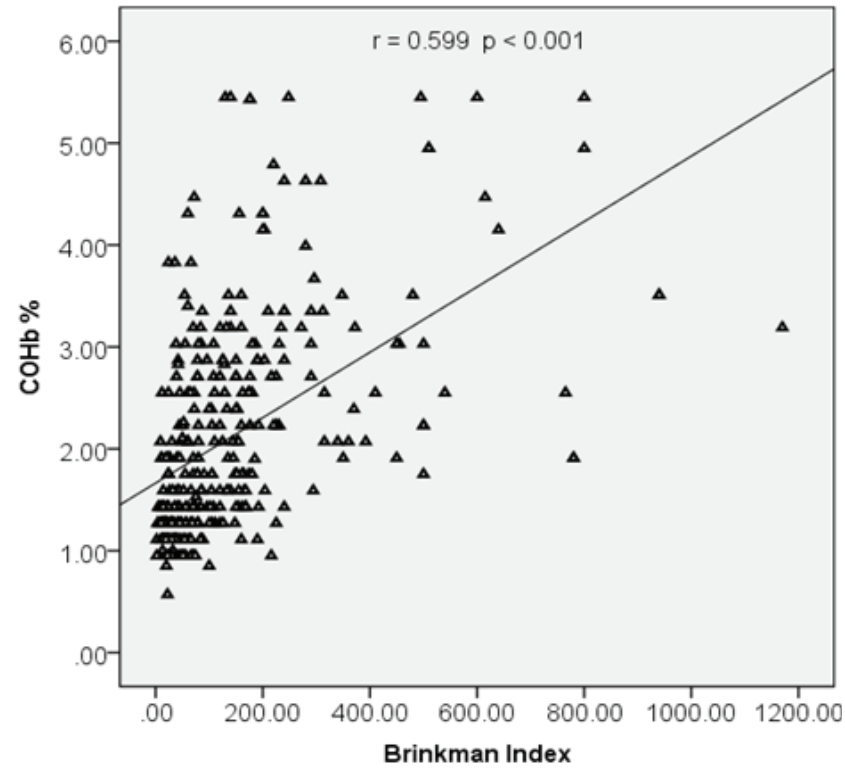

(B) 
Figure 4. Correlation between the time duration from the last cigarette smoked with (A) eCO levels, and

(B) $\mathrm{COHb} \%$ levels of smokers

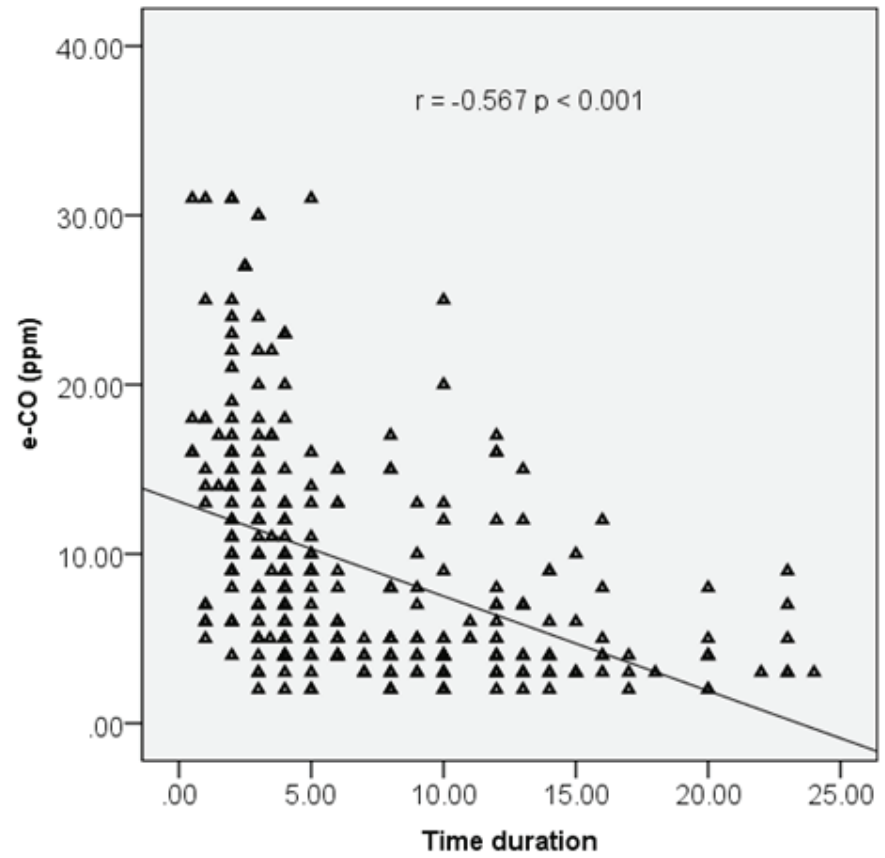

(A)

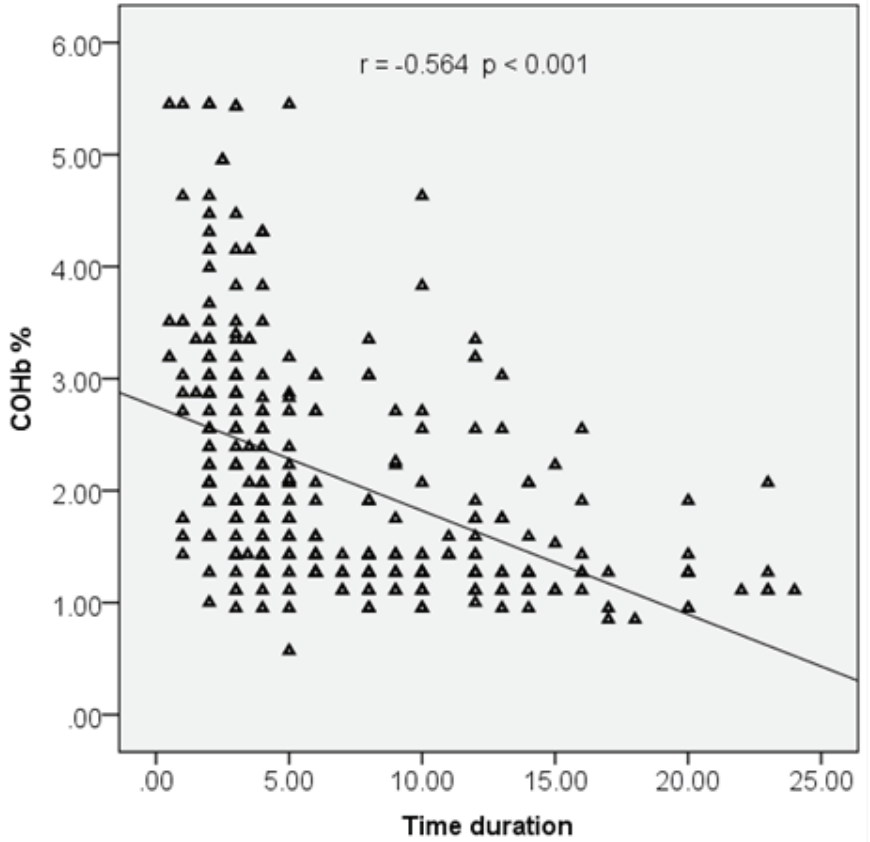

(B) positive correlation with Brinkman index and MCV ( $\mathrm{r}=0.227$, $\mathrm{p}=0.002), \mathrm{MCH}(\mathrm{r}=0.270, \mathrm{p} \leq 0.001)$, and total granulocyte count $(\mathrm{r}=0.153, \mathrm{p}=0.043)$.

\section{DISCUSSION}

This study was conducted to assess the effects of tobacco smoking on exhaled breath carbon monoxide (eCO), blood carboxyhemoglobin levels ( $\mathrm{COHb} \%)$, and hematological parameters, amongst Sri Lankan adult male tobacco smokers. Sri Lanka currently lacks baseline values for the aforementioned characteristics in its smoking population. These baseline values and associations will be important in the development of smoking cessation studies; a more indepth study into the physiological response to low-intensity tobacco smoking is needed.

Smokers' values were compared with weight, height, BMI and age-matched non-smokers $(p>0.05)$ to improve the scientific validity of the study. eCO has been used in many studies ${ }^{14,16,22-24,37,38}$ to assess the smoking status of tobacco smokers. Combusted cigarettes produce $\mathrm{CO}$ which enters the bloodstream by diffusion at the pulmonary capillaries. $\mathrm{CO}$ has a high affinity to hemoglobin and binds to hemoglobin in red blood cells and was measured as $\mathrm{COHb} \%$ in the present study. According to the literature, $85 \%$ of $\mathrm{CO}$ in the body is attached to hemoglobin in circulating red blood cells, and the majority of the remaining $\mathrm{CO}$ is linked with myoglobin in the muscles ${ }^{39}$. The eCO is in dynamic equilibrium with $\mathrm{COHb} \%$. The present study is the first study conducted in Sri Lanka to determine the severity of smoking taking the eCO and $\mathrm{COHb} \%$ into consideration. CO levels in breath can be influenced by many factors such as diet, exercise, inflammation, and time of the day ${ }^{23}$. It is believed that $\mathrm{CO}$ is produced endogenously, mainly through oxidative stress and inflammation of lung diseases such as COPD and asthma. However, a study has observed that there is no significant difference in $\mathrm{CO}$ values of smokers with normal lung function compared to smokers with COPD ${ }^{23}$.

In this study, there was a statistically significant higher eCO concentration and $\mathrm{COHb} \%$ of smokers than nonsmokers. The results of the study are in line with other studies ${ }^{16,24,37}$. Further, the present study showed a strong positive correlation between eCO and $\mathrm{COHb} \%$ with the number of cigarettes smoked per day, duration of smoking ${ }^{22,24,37}$ and Brinkman index. Besides, there was a strong negative correlation between eCO levels as well as $\mathrm{COHb} \%$ with the time from the last cigarette. Therefore, the measurement of smoking through the assessment of eCO can be objectively used to assess the smoking status. In a primary care setup, it is very important to identify current smokers, in order to deliver quitting advice and to promote quitting and adherence to quitting amongst smokers. Further, as the method of testing is easy to conduct, eCO measurement further promotes better monitoring of patients who have still not quit smoking.

Measurement of eCO is more practical and easier to sustain in low-cost healthcare delivery settings such as in Sri 
Lanka. It is practically difficult in primary care to determine cotinine levels in the blood and other samples as it is not cost-effective ${ }^{40}$. Further, the cotinine levels are known to vary depending on the ethnic group. A portable exhaled breath CO monitor is a cost-effective calibrated device which is easy to administer in a clinic setting. Further, the results are immediately available to the healthcare provider as well as to the patient, so that eCO level can be easily determined. Therefore, a portable CO monitor is a highly reliable tool to assess smoking severity. Once current smokers are identified with the eCO monitor, it will help to deliver more effective counseling sessions for them ${ }^{24,41}$, as both the counselor and smoker can have an excellent quick assessment of smoking status or the success of quitting attempts.

Robust scientific evidence exists to support the relationship between smoking and cardiovascular illness ${ }^{42,43}$. The exact mechanisms of the onset of disorders due to smoking cigarettes are unknown, but these effects are thought to be caused by changes in blood physiology, infections and inflammation, oxidative stress and antithrombotic effects, and changes in the fibrinolysis system ${ }^{13}$. Smoking causes alterations in various hematological parameters ${ }^{13,41}$. The present study confirmed that smokers had significantly higher levels of total white blood cell (WBC) counts, lymphocyte counts, monocyte counts, and granulocyte count, compared to non-smoker controls. Increasing WBC counts is a simple marker for endothelial injury ${ }^{43}$. Similar to our study, Acik et al. ${ }^{21}$ found higher WBC, neutrophil, eosinophil, monocyte, and lymphocyte counts, compared to non-smokers.

Exposure to the irritant chemicals of tobacco smoke causes inflammation of the bronchial mucosa which increases the WBC counts. Further, an increase in WBC count has been described as a risk factor for subclinical atherosclerosis as well as vascular wall thickening ${ }^{43}$. Similar leukocytosis has been observed in other studies ${ }^{25,26}$. Although the exact mechanism of leukocytosis is not fully clarified, and smoking-induced leukocytosis may be due to several factors, and it may be explained in different ways. Leukocytosis may be the result of the nicotine-induced release of catecholamine and steroid hormones from the adrenal gland. It is known that an increase in the level of certain endogenic hormones, such as epinephrine and cortisol, increases the number of circulating leukocytes ${ }^{27,28}$.

WBC, platelet and red blood cell production in bone marrow increases due to stimulation by erythropoietin as a response to CO-mediated hypoxia ${ }^{21}$. This, in turn, leads to increased hemoglobin levels. According to the present study, we assessed all subgroups of leukocytes, which were also significantly higher in smokers than nonsmokers. Furthermore, the average cigarette consumption of our selected population is not high though they had this significantly higher leukocyte level compared to the nonsmokers. This is significant evidence to confirm that there is no safe level of smoking for an individual's health.
According to the findings, smokers had significantly higher levels of hemoglobin ( $\mathrm{Hb}$ ) values and this may be due to the CO-mediated stimulation of hypoxia inducing greater production of hemoglobin. Carbon monoxide binds to $\mathrm{Hb}$ and forms carboxyhemoglobin, an inactive form of hemoglobin that cannot carry oxygen. Carboxyhemoglobin also alters the $\mathrm{Hb}$ degradation curve on the left side, resulting in a decreased ability of $\mathrm{Hb}$ to deliver oxygen to tissue. To compensate for the reduced oxygen supply, smokers maintain higher hemoglobin levels than non-smokers ${ }^{13,21}$. The synthesis of erythropoietin in renal capillary tubular cells increases in response to hypoxia. These significant elevations in hemoglobin level are in accordance with previous studies $^{13,21}$. This is known to account for the higher levels of hemoglobin of smokers of the present study.

The present study established significantly larger values of $\mathrm{MCV}, \mathrm{MCH}$, and $\mathrm{MCHC}$, amongst smokers compared to non-smokers. Similar increases in the red cell indices have been observed with significantly larger values of MCV and $\mathrm{MCH}$ among smokers, while differences in values of MCHC were not significant between smokers and non-smokers ${ }^{13}$. $\mathrm{MCV}, \mathrm{MCH}$, and MCHC, are the three main red blood cell indices that help in measuring the average size of red cells and the hemoglobin structure of the red blood cells. MCH is the average weight of hemoglobin that is present inside a single red blood cell whereas MCHC denotes the amount of hemoglobin in a specific volume of 'packed' red corpuscles or cells. Further, a significant, positive correlation between Brinkman index and MCV, MCH, and granulocytes count, was also identified. Thus, this study established a relationship between the Brinkman index and hematological parameters. In addition to that, there was a significant positive correlation between the number of cigarettes smoked per day and MCV and MCH.

This study supports the idea that prolong cigarette smoking has adverse effects on the hematologic parameters $^{28}$. Prolonged smoking exposure seems to have contributed to inducing the above changes of hemoglobin within the red cells. There was no significant difference in RBC count and that finding is compatible with the study conducted by Malenica ${ }^{13}$. However, a study conducted by Sherke et al. ${ }^{43}$ found that the RBC count too increased with smoking among adult males. The present study did not find any difference between smokers and non-smokers in terms of platelet count. This finding is consistent with other studies $^{43}$.

\section{Strengths and limitations}

Our research has many strengths. We used a random sampling methodology to choose the sample. The sample size was large, with 540 participants. The fact that we selected age and anthropometric parameters matched non-smokers to match with smokers was our greatest strength. All measurements were taken with calibrated standard equipment. Furthermore, this is the first study 
ever conducted in Sri Lanka amongst smokers to estimate the effects of tobacco smoking on exhaled breath carbon monoxide (eCO) levels, blood carboxyhemoglobin levels ( $\mathrm{COHb} \%)$, and hematological parameters, amongst adult male tobacco smokers. Our research has several limitations. We did not do a subgroup analysis because this is cross-sectional research. However, we selected them in a standard manner. Furthermore, their smoking history was approximated based on their verbal response.

\section{CONCLUSIONS}

Cigarette smoking is associated with a significant increase of exhaled breath $\mathrm{CO}$ as well as $\mathrm{COHb} \%$ level and it is positively correlated with the number of cigarettes smoked per day and the Brinkman index. Measurement of eCO using a CO monitor is a quick, non-invasive, cost-effective easy and efficient test to confirm the patient's smoking status. Continued cigarette smoking is associated with alterations of peripheral red cell counts, red cell indices, and white cell counts. These alterations might be associated with a greater risk for developing cardiovascular diseases subsequent to long-term smoking. The present study was rigorously conducted to confirm some of the known effects of cigarette smoking hitherto not estimated in the Sri Lankan population. The purchase of the monitor although expensive to initially purchase is relatively maintenance-free and does not involve costly calibration methods. These simple methods can be used effectively to deliver better healthcare and facilitate the quit smoking efforts of Sri Lankan smokers.

\section{REFERENCES}

1. Elkhadragy $\mathrm{N}$, Christ SL, Bashawri Y, AlSaran H. Physicians' self-efficacy, beliefs and intentions to provide tobacco cessation services: A cross-sectional study in Riyadh, Saudi Arabia. Popul Med. 2021;3(April):1-9. doi:10.18332/popmed/134658

2. Chander SJU, Santhakumar S, Solomon SWD. Study protocol to assess the effectiveness of pharmacistmanaged stopsmoking services : A randomized controlled trial. Popul Med. 2020;2(February):1-6. doi:10.18332/popmed/118243

3. Cai Y, Xu W, Liu H, et al. Effects of cigarette smoking on older chinese men treated with clopidogrel monotherapy or aspirin monotherapy: a prospective study. Platelets. 2020;31(5):667-673. doi:10.1080/09537104.2019.1667494

4. Bernstein SL, Toll BA. Ask about smoking, not quitting: a chronic disease approach to assessing and treating tobacco use. Addict Sci Clin Pract. 2019;14:29. doi:10.1186/s13722-019-0159-z

5. World Health Organization, Pan American Health Organization. Tobacco control. Accessed September 27, 2021. https://www.paho.org/en/topics/tobaccoprevention-and-control

6. Oyapero A, Olatosi 00, Olagundoye O. Are Nigerian oral health workers overlooking opportunities to promote interventions for tobacco smoking cessation? Popul Med.
2021;3(February):1-7. doi:10.18332/popmed/132292

7. World Health Organization. Tobacco fact sheet. World Health Organization; 2020. Accessed September 4, 2020. https:// www.who.int/en/news-room/fact-sheets/detail/tobacco

8. Ahmed MS, Sayeed A, Jahan I, Dewan MF, Mali SK. Prevalence and factors associated with cigarette smoking among resident university students: A crosssectional study from Bangladesh. Popul Med. 2020;2(February):1-6. doi:10.18332/popmed/118250

9. BURDEN OF TOBACCO. ADIC Sri Lanka. Accessed September 4, 2020. http://adicsrilanka.org/facts-on-tobacco/

10. Tobacco Control Research Group. Sri Lanka- Country Profile. TobaccoTactics. Updated September 29, 2021. Accessed September 4, 2020. https://tobaccotactics.org/wiki/srilanka-country-profile/

11. Tobacco Industry Country Profile - Sri Lanka. TobaccoUnmasked. Updated June 15, 2021. Accessed September 4, 2021. https://www.tobaccounmasked. com / index.ph p / Tobacco_Industry_Country_ Profile_\%E2\%80\%93_Sri_Lanka

12. World Health Organization. 10 WHO prevalence estimates. Web Annex VI: Global Tobacco Control Policy Data. World Health Organization; 2021. Accessed September 2, 2021. https://www.who.int/publications/i/item/WHO-HEP-HPRTFI-2021.10

13. Malenica M, Prnjavorac B, Bego T, et al. Effect of Cigarette Smoking on Haematological Parameters in Healthy Population. Med Arch. 2017;71(2):132-136. doi:10.5455/medarh.2017.71.132-136

14. Caponnetto P, Maglia M, Prosperini G, Busà B, Polosa R. Carbon monoxide levels after inhalation from new generation heated tobacco products. Respir Res. 2018;19(1):164. doi:10.1186/s12931-018-0867-z

15. Selya AS, Hesse ND. Time to first cigarette and serum cholesterol levels. Soc Sci Med. 2017;174:213-219. doi:10.1016/j.socscimed.2016.12.014

16. Jarvis MJ, Russell MA, Saloojee Y. Expired air carbon monoxide: a simple breath test of tobacco smoke intake. Br Med J. 1980;281(6238):484-485. doi:10.1136/bmj.281.6238.484

17. Goodwin RD, Lavoie KL, Lemeshow AR, Jenkins E, Brown ES, Fedoronko DA. Depression, anxiety, and COPD: the unexamined role of nicotine dependence. Nicotine Tob Res. 2012;14(2):176-183. doi:10.1093/ntr/ntr165

18. Selya AS, Oancea SC, Thapa S. Time to First Cigarette, a Proxy of Nicotine Dependence, Increases the Risk of Pulmonary Impairment, Independently of Current and Lifetime Smoking Behavior. Nicotine Tob Res. 2016;18(6):1431-1439. doi:10.1093/ntr/ntv291

19. Doll R, Peto R, Boreham J, Sutherland I. Mortality from cancer in relation to smoking: 50 years observations on British doctors. Br J Cancer. 2005;92(3):426-429. doi:10.1038/sj.bjc.6602359

20. Hecht SS. Tobacco smoke carcinogens and lung cancer. J Natl Cancer Inst. 1999;91(14):1194-1210. doi:10.1093/jnci/91.14.1194 
21. Acik DY, Suyani E, Aygun B, Bankir M. The Effect of Smoking on Hematological Parameters. The ulutas medical journal. 2020;6(1):9-14. doi:10.5455/umj.20200209092535

22. Low ECT, Ong MCC, Tan M. Breath carbon monoxide as an indication of smoking habit in the military setting. Singapore Med J. 2004;45(12):578-582.

23. Sandberg A, Sköld CM, Grunewald J, Eklund A, Wheelock ÅM. Assessing recent smoking status by measuring exhaled carbon monoxide levels. PLoS One. 2011;6(12):e28864. doi:10.1371/journal.pone.0028864

24. Deveci SE, Deveci F, Açik Y, Ozan AT. The measurement of exhaled carbon monoxide in healthy smokers and non-smokers. Respir Med. 2004;98(6):551-556. doi:10.1016/j.rmed.2003.11.018

25. Bain BJ, Rothwell M, Feher MD, Robinson R, Brown J, Sever PS. Acute changes in haematological parameters on cessation of smoking. J R Soc Med. 1992;85(2):80-82.

26. Roy A, Sikdar J, Seal P, Haldar R. Cigarette smokers develop structurally modified hemoglobin: a possible way of increasing oxidative stress. Inhal Toxicol. 2015;27(6):300307. doi:10.3109/08958378.2015.1045052

27. Drope J, Schluger NW, Cahn Z, et al. The Tobacco Atlas. American Cancer Society, Vital Strategies; 2018. Accessed September 12, 2021. https://tobaccoatlas.org/wp-content/ uploads/2018/03/TobaccoAtlas_6thEdition_LoRes_ Rev0318.pdf

28. Batic-Mujanovic O, Beganlic A, Salihefendic N, Pranjic $\mathrm{N}$, Kusljugic Z. Influence of smoking on serum lipid and lipoprotein levels among family medicine patients. Med Arh. 2008;62(5-6):264-267.

29. Moradinazar M, Pasdar Y, Najafi F, et al. Association between dyslipidemia and blood lipids concentration with smoking habits in the Kurdish population of Iran. BMC Public Health. 2020;20(1):673. doi:10.1186/s12889-020-08809-z

30. Boksa P. Smoking, psychiatric illness and the brain. J Psychiatry Neurosci. 2017;42(3):147-149. doi:10.1503/jpn.170060

31. Lawrence D, Mitrou F, Zubrick SR. Smoking and mental illness: results from population surveys in Australia and the United States. BMC Public Health. 2009;9:285. doi:10.1186/1471-2458-9-285

32. Jain RB, Ducatman A. Associations between smoking and lipid/lipoprotein concentrations among US adults aged $\geq 20$ years. J Circ Biomark. 2018;7:1-10. doi:10.1177/1849454418779310

33. Hata K, Nakagawa T, Mizuno M, et al. Relationship between smoking and a new index of arterial stiffness, the cardio-ankle vascular index, in male workers: a cross-sectional study. Tob Induc Dis. 2012;10(1):1-5. doi:10.1186/1617-9625-10-11

34. Arumsari D, Martini S, Artanti KD, Widati S. THE DESCRIPTION OF SMOKING DEGREE BASED ON BRINKMAN INDEX IN PATIENTS WITH LUNG CANCER. Jurnal Berkala Epidemiologi. 2019;7(3):249-256. doi:10.20473/jbe.V7I32019.250-257

35. Bahadir A, Iliaz S, Yurt S, Ortakoylu MG, Bakan ND, Yazar
E. Factors affecting dropout in the smoking cessation outpatient clinic. Chron Respir Dis. 2016;13(2):155-161. doi:10.1177/1479972316629953

36. Katulanda P, Wickramasinghe K, Mahesh JG, et al. Prevalence and correlates of tobacco smoking in Sri Lanka. Asia Pac J Public Health. 2011;23(6):861-869. doi:10.1177/1010539509355599

37. Vasthare R, Kumar S, Arron LYR. Carbon monoxide breath analyzers and its role in tobacco cessation: A narrative review of literature. J Int Oral Health. 2018;10(2):71-76. doi:10.4103/jioh.jioh_273_17

38. Cropsey KL, Eldridge GD, Weaver MF, Villalobos GC, Stitzer ML. Expired Carbon Monoxide Levels in Self-Reported Smokers and Nonsmokers in Prison. Nicotine Tob Res. 2006;8(5):653-659. doi:10.1080/14622200600789684

39. Deller A, Stenz R, Forstner K, Konrad F. Die Elimination von Kohlenmonoxydhämoglobin - Geschlechtsspezifische und zirkadiane Einflüsse. 1992;19(3):121-126. doi:10.1159/000222600

40. Signorello LB, Cai Q, Tarone RE, McLaughlin JK, Blot WJ. Racial differences in serum cotinine levels of smokers. Dis Markers. 2009;27(5):187-192. doi:10.3233/DMA-2009-0661

41. Pita-Fernández S, Seijo-Bestilleiro R, Pértega-Díaz S, et al. A randomized clinical trial to determine the effectiveness of CO-oximetry and antismoking brief advice in a cohort of kidney transplant patients who smoke: study protocol for a randomized controlled trial. Trials. 2016;17:174. doi:10.1186/s13063-016-1311-7

42. Inal B, Hacibekiroglu T, Cavus B, Musaoglu Z, Demir H, Karadag B. Effects of smoking on healthy young men's hematologic parameters. North Clin Istanb. 2014;1(1):1925. doi:10.14744/nci.2014.39974

43. Sherke BA, Vadapalli K, Bhargava DV, Sherke AR, Gopireddy MMR. Effect of number of cigarettes smoked per day on red blood cell, lecocyte and platelet count in adult Indian male smokers - A case control study. International journal of medical research \& health sciences. 2016;5(2):13-17. Accessed September 12, 2021. https://www.ijmrhs.com/ medical-research/effect-of-number-of-cigarettes-smokedper-day-on-red-blood-cell-lecocyte-and-platelet-count-inadult-indian-male-smokers.pdf 
ACKNOWLEDGEMENTS

Our sincere thanks to the participants, medical administrators, and healthcare employees who assisted in this study.

\section{CONFLICTS OF INTEREST}

The authors have completed and submitted the ICMJE Form for Disclosure of Potential Conflicts of Interest and none was reported.

\section{FUNDING}

The project was financially supported by a research grant (ASP/01/RE/ MED/2016/55) of the University of Sri Jayewardenepura. The funders had no role in the design of the study; in the collection, analysis, or interpretation of data; in the writing of the manuscript, or in the decision to publish the results.

\section{ETHICAL APPROVAL AND INFORMED CONSENT}

Ethical approval was obtained from the ethics review committee of the Faculty of Medical Sciences, University of Sri Jayewardenepura
(ERC application 23/17). Participants were recruited to the study after obtaining written permission from the respective Provincial Director of Health - Western Province, Regional Director of Health.

\section{DATA AVAILABILITY}

The data supporting this research cannot be made available for privacy reasons.

\section{AUTHORS' CONTRIBUTIONS}

$\mathrm{PH}, \mathrm{SW}, \mathrm{TA}, \mathrm{MF}$ and ST conceived and designed the study. PH performed the study. PH, SW, TA and MF were involved in data interpretation and statistical analysis. PH wrote the first draft of the manuscript. SW, TA, MF and ST critically revised the manuscript for intellectual content. All authors read and approved the final manuscript. All authors are responsible for the academic content of the article.

PROVENANCE AND PEER REVIEW

Not commissioned; externally peer reviewed. 